\title{
O sistema de saúde do escravo no Brasil do século XIX: doenças, instituições e práticas terapêuticas
}

\author{
The healthcare system for slaves in nineteenth-century Brazil: \\ disease, institutions, and treatment practices
}

\section{Ângela Pôrto}

Pesquisadora da Casa de Oswaldo Cruz - Fiocruz

Av. Brasil, 4365 - 21040-900

Rio de Janeiro - RJ - Brasil

aporto@coc.fiocruz.br
PÔRTO, A.: O sistema de saúde do escravo no Brasil do século XIX: doenças, instituições e práticas terapêuticas.

História, Ciências, Saúde-Manguinhos,

Rio de Janeiro, v. 13, n. 4, p. 1019-27, out.-dez. 2006.

O século XIX é marcado por várias tentativas de coibir o tráfico de escravos e, ao mesmo tempo, é o período em que a importação foi a maior da história brasileira. As condições de transporte dos escravos, suas condições de trabalho, moradia e modo de vida são em grande parte responsáveis por suas condições de saúde. No entanto, essa questão só aparece pelas frestas da história e apresenta muitos pontos controversos a serem esclarecidos. O interesse da pesquisa é promover o cruzamento de fontes e temas, que reúnam uma variedade de informações sobre a vida higiênica dos escravos no século XIX. Nosso objetivo é reunir uma massa de dados, a partir da análise de documentos dos arquivos hospitalares, cartoriais e eclesiásticos, das fontes iconográficas e da literatura médica, que nos dêem elementos para compor uma história do sistema de saúde dos escravos.

PALAVRAS-CHAVE: escravidão; história de doenças; história da medicina; história do Brasil; século XIX.

PÔRTO, A.: The healthcare system for slaves in nineteenthcentury Brazil: disease, institutions, and treatment practices. História, Ciências, Saúde-Manguinhos, Rio de Janeiro, v. 13, n. 4, p. 1019-27, Oct.-Dec. 2006.

Although the nineteenth century saw numerous attempts to deter the slave trade, it was also the period when Brazil imported the greatest number of slaves in its history. The conditions under which slaves were transported, worked, and lived were largely responsible for their state of health. Yet this topic barely makes an appearance in the field of history, and many disputed points remain to be settled. My research cross-references sources and topics in order to gather data on the hygienic lives of nineteenth-century slaves. By analyzing archival documents from hospitals, notary public offices, and church bodies, iconographic sources, and the medical literature, I have retrieved information that can be used towards writing a history of the healthcare system available to slaves.

KEYWORDS: slavery; history of diseases; history of medicine; history of Brazil; nineteenth century. 
$\mathrm{O}$ tráfico de escravos africanos é um aspecto da história que marcou em profundidade nossa experiência. Esse comércio deslocou seres humanos de seus lugares de origem para viverem em cativeiro e sob condições absolutamente adversas. Como observou Luiz Felipe de Alencastro (2000, p. 127), o processo de expansão ultramarina, iniciado nos séculos XV e XVI, além de ampliar o trânsito de mercadorias e os contatos entre os povos, representou a "união microbiana do mundo", por incrementar o trânsito de doenças. O século XIX, período ao qual vamos nos ater, marca, no Brasil, a ocorrência da maior importação de escravos e de mudanças institucionais decisivas que levaram à abolição do tráfico e da escravidão. Foi também o momento da estruturação do ensino médico no Brasil, com a criação das Faculdades de Medicina de Salvador e do Rio de Janeiro, cidades cujos portos receberam, no período, o maior número de escravos. As condições de transporte dos escravos, suas condições de trabalho, moradia e modo de vida são em grande parte responsáveis por suas condições de saúde. No entanto, a questão da saúde do escravo só aparece pelas frestas da história e apresenta muitos pontos controversos a serem esclarecidos.

Há muito que o mito do senhor benevolente, a partir de interpretações da obra de Gilberto Freyre (1933), caiu por terra. Outros mitos, no entanto, ainda persistem e confundem a compreensão da história da escravidão no Brasil, tais como ter havido uma negligência absoluta dos senhores para com a saúde dos seus cativos ou de os escravos terem sido totalmente dependentes, incapazes de agir sobre sua própria saúde. A partir dos anos 70, ocorre uma mudança de paradigmas na história social do Brasil, com o aparecimento de trabalhos, como o de Kátia Mattoso em Ser escravo no Brasil. A partir daí, o escravo é cada vez mais compreendido como capaz de construir redes de solidariedades, de possuir sistemas de valores próprios e capacidade de preservar e transmitir sua herança cultural. O sincretismo é a marca da cultura no Brasil, forjado por contribuições das mais diversas etnias e patente em várias manifestações. A contribuição da cultura africana também se faz presente em nossas práticas de saúde, mas tal presença não está ainda bem identificada e carece de estudo mais detalhado.

O discurso médico do século XIX vê no negro escravo a causa de muitos males, sua presença no seio da família é corruptora, representando perigo físico e moral. Muito embora, para o pensamento médico higienista do Século XIX, não prevalecessem assertivas de origem racial, pesam mais os fatores sociais, os associados às condições de vida (Maio, 2004). Poucas foram as propostas oficiais de atenção à saúde dos escravos, e menos ainda as que foram acompanhadas por medidas que nem sequer eram cumpridas, como observou Mercês Somarriba, em estudo pioneiro sobre a medicina no escravismo colonial (Somarriba, 1984). Apenas três livros que trataram da questão 
foram publicados com o apoio do Estado, sendo, portanto, revestidos de caráter oficial. São eles os manuais de Jean-Baptiste Imbert (1834), Carlos Augusto Taunay (1839) e Antônio Caetano da Fonseca (1863), obras carregadas de conselhos higiênicos dirigidas aos proprietários rurais. Tratam de aspectos gerais da saúde dos cativos, que possam interessar aos senhores proprietários. Observam como escolher no mercado uma peça saudável, como deve ser a constituição física do escravo, suas condições de habitação, vestuário, alimentação, jornada de trabalho, repouso, castigos etc. A instrução religiosa é aconselhada como "higiene moral", necessária para a submissão do escravo, sua adaptação à sociedade e o bom andamento do trabalho. Esses manuais dirigidos aos fazendeiros trazem a relação das principais enfermidades que acometem os negros e o tratamento caseiro que pode ser facilmente administrado pelos senhores. Assemelham-se aos manuais médicos mais utilizados à época tais como o de Chernoviz (1841) e Langaard (1873).

Não obstante o caráter oficial dessas obras, nenhuma delas sugere a criação de um serviço destinado ao tratamento médico de escravos. Assim, observa-se, na literatura coeva à escravidão, a inexistência de uma preocupação com a prática médica voltada para a força de trabalho escrava. Em "O Negro no pensamento médico", os autores de Danação da norma (Machado, 1976) concluem ser o escravo uma reflexão secundária para a medicina oficial. Fundamentam-se na constatação da insignificância do número de teses sobre o assunto nas academias. Na Faculdade de Medicina do Rio de Janeiro, apenas três teses elegendo essa temática foram defendidas (Duarte, 1849; Jardim, 1847; Souza, 1851) e o tema está praticamente ausente nas publicações da Sociedade de Medicina, entre 1831 e 1890. A saúde do escravo não é diretamente tematizada, o assunto só surge em relação a outrem, como por exemplo a saúde da escrava ama-de-leite que exerce a chamada "amamentação mercenária" com a criança do senhor, e o perigo que o escravo representa para a saúde no meio doméstico ou para toda a sociedade, como responsável pela transmissão de diversas moléstias.

Sem tirar o mérito desses trabalhos é necessário retomar a questão. Esses estudos imprimiram, de uma certa forma, a idéia geral de que o escravo - mal alimentado, mal vestido e maltratado - tanto no campo como na cidade, era explorado ao máximo de suas forças, obrigado a cumprir uma longa jornada de trabalho. Os proprietários só se tornavam mais cuidadosos com seus escravos quando suas reservas diminuíam por efeito de uma epidemia, e freqüentemente os sintomas de doenças eram desprezados como "fingimento" para faltar ao trabalho. Os maus tratos dos senhores encontravam limites mais no medo de perder o escravo pela morte ou pela fuga, e no respeito à opinião pública, que nas leis que o protegiam, pois estas raramente se cumpriam. Normalmente praticava-se 
o que parecia dar bons resultados para prolongar a vida dos escravos para o trabalho.

Estudos recentes acrescentam novas idéias à análise da questão da saúde do escravo. $O$ tratamento dispensado ao cativo pode variar de acordo com sua situação: nas fazendas pequenas ou nas pertencentes ao clero (Assunção, 2002), por exemplo, podem ser mais bem tratados que nas grandes fazendas monocultoras (Stein, 1961 e 1990; Falci, 2004). Tudo pode depender, portanto, das relações estabelecidas com seu dono. O escravo urbano é com freqüência mais independente diante de seu senhor que o rural; goza de maior liberdade de ação e conta com os laços de solidariedade de outros escravos ou de forros que abundam nas cidades, organizados em confrarias e irmandades (Carvalho Soares, 2000; Mattoso, 1982; Algranti, 1988; Chalhoub, 1996; Dias, 1985). Também podemos observar a partir da leitura de memórias e relatos de viajantes estrangeiros (Binzer, 1998; Marques, 1922; Werneck, 1986) que os senhores, isolados nas fazendas, lançavam mão freqüentemente dos recursos locais para os casos mais graves de doença. Curandeiros, quimbandeiros, feiticeiros eram chamados na ausência dos médicos itinerantes, que só percorriam de tempos em tempos as fazendas. A ausência dos médicos, no entanto, não parece ser determinante no recurso que se fazia aos curandeiros, feiticeiros ou rezadores. A concepção de que a origem das doenças tinha uma natureza sobre-humana explica melhor tal atitude e justifica também o uso de amuletos para se proteger não apenas de doenças, mas de toda sorte de infortúnios (Soares, 2001, p. 407-38).

Apesar do investimento representado por cada escravo, nem todos os proprietários cuidaram adequadamente da escravaria. Essa é uma questão que merece atenção: a contradição de se cuidar de uma 'coisa' que não é 'sujeito', pois o escravo é visto como mercadoria. Mas mercadoria tem valor. A partir da segunda metade do século XIX, com o maior controle sobre o tráfico de escravos, notase uma preocupação mais consistente dos senhores com a preservação da mão-de-obra escrava, já que a oferta se tornara mais escassa, mas não sua demanda, o que provoca a valorização do preço das 'peças'. Os proprietários procuram então dar melhor tratamento aos escravos, sem lhes reduzir a jornada de trabalho, numa tentativa de prolongar-lhes a vida útil. Essa é, no entanto, uma questão relativa que pode variar de acordo com a região, pois, apesar de constituir-se como mercadoria investida de valor, nem sempre a situação do escravo era percebida como tal. Apesar de a saúde dos escravos ser precondição na fixação do seu valor, soluções baratas adotadas pelos proprietários de escravos, no fornecimento de moradia, alimentos, roupas ou remédios, fizeram proliferar doenças entre eles. As mais comuns eram as doenças decorrentes dos maus-tratos físicos ou do trabalho fatigante. Como a alta incidência de doenças pulmonares 
demonstrada por Mary Karasch (2000), com base na estatística da Santa Casa de Misericórdia do Rio de Janeiro.

Mas as doenças dos escravos e as doenças dadas como de origem africana são um tema que deve ser retomado. Não podemos afirmar, como o fizeram os historiadores da medicina do passado, que determinadas doenças foram introduzidas pelos negros africanos, ou mesmo que eram exclusivas deles. Quanto às doenças adquiridas pelos negros aos brancos, sobretudo os escravos domésticos, situação apontada por Freyre em Casa grande e senzala (1933), a preocupação de médicos e historiadores parece ter sido menor. Algumas análises como as de Rodrigues (2004 e 1935) e Freitas (1935) têm uma visão determinista biológica, e refletem, portanto, a concepção da influência racial das doenças, e outros como Santos Filho (1991) e Parahym (1978) contribuíram para reforçar estereótipos sobre a população negra, na medida em que não retomam à luz de novos conhecimentos essa questão e reafirmam a existência de doenças de origem africana, sem ressalvas. Xavier Sigaud (1844) creditou aos negros a prevalência de patologias específicas, mas não como resultado de sua composição racial, e sim da influên-cia exercida pelo clima (Ferreira, 1996).

Estudos recentes de paleopatologia têm esclarecido um pouco mais essa questão, mostrando que o achado de parasitas ou de lesões em fósseis indicam a presença de algumas dessas doenças antes da chegada do homem branco à América. Portanto, a ausência de uma doença não significa que ela não possa ocorrer, tudo pode depender das condições propícias para seu aparecimento, como por exemplo, contatos recentes entre populações provocando mudanças no modo de vida, alimentação etc. (McNeil, 1989). Sobre a questão da saúde e da doença do escravo no Brasil (Silva, 2004), resultados preliminares começam a surgir nos estudos desenvolvidos em paleopatologia por Luiz Fernando Ferreira, Sheila Mendonça e Diana Maul, que dão nova feição à questão da origem das doenças. Quanto às investigações recentes em demografia histórica que nos fornecem novos dados sobre a população de ascendência africana, vejam-se os estudos de Manolo Florentino e Roberto Góes e as pesquisas sobre a história da família escrava no Brasil desenvolvidos por Robert Slenes e Sheila Faria. O crescente intercâmbio entre disciplinas nos permite hoje um melhor entendimento da questão da escravidão e do papel do negro na sociedade brasileira.

Finalmente, não podemos nos esquecer do importante papel desempenhado pelos negros em relação a seu próprio tratamento médico. Esse campo de estudo se alargou nos últimos anos e revela farta documentação para a elaboração de uma análise mais aprofundada sobre a medicina entre os escravos (Chalhoub, 2003; Figueiredo, 2002; Pimenta, 1998 e 2003; Sampaio, 2000 e 2001; Witter, 2001). A medicina africana em diversas situações mostrou-se mais eficaz aos olhos da população negra da Corte e, embora os considerassem 
charlatães, muitos brancos também arriscavam usar os serviços oferecidos pelos negros. O convívio próximo no cotidiano da cidade facilitou muito o intercâmbio cultural entre senhores e escravos (Soares, 2001). As lojas de barbeiro abundam nas cidades e, em geral, seus proprietários são negros ou mulatos, hábeis cirurgiões na arte de sangrar e aplicar sanguessugas. Também a presença de sangradores e curandeiros nos quadros da Santa Casa de Misericórdia já foi atestada (Pimenta, 2003) e não se limitava apenas à aplicação de sanguessugas ou à sangria: "O sangrador, de certa forma, ilustra a permeabilidade entre dois pólos de medicina - a acadêmica e a popular". A prática médica no Brasil resulta de trocas e apropriações de experiências entre europeus, índiose africanos. Esse amálgama de saberes enriquece, desde os tempos da Colônia, o receituário de mezinhas domésticas que constitui prática bastante comum no Brasil no século XIX, tanto na zona rural como nas cidades.

Os estrangeiros que por aqui estiveram constataram a estreita relação entre as condições de vida e trabalho dos escravos e as doenças que mais comumente os acometiam. É na crônica de viajantes que encontramos observações associando a grande incidência de moléstias e disfunções à má alimentação e aos maus-tratos. Sendo, portanto, importante fonte para se traçar a história doenças dos escravos. Podemos também apreciar nos relatos dos viajantes observações espantadas quanto ao uso e o efeito de ervas e feitiços, pelos negros, no tratamento de enfermidades. "Os negros servem-se, em geral, de remédios baseados nas crendices que trouxeram da pátria, atravessando o mar, e que conservam zelosamente", escreve o médico Johann Emmanuel Pohl, em 1818. As relações dos escravos com a saúde estão associadas a outra lógica de explicação da doença. Um estudo mais amplo do legado do negro à prática médica ainda está por fazer.

A questão da saúde e da doença do escravo tem sido analisada apenas indiretamente nos trabalhos acadêmicos sobre a escravidão em geral. Neste aspecto, a historiografia nacional carece de estudos específicos, se comparada à produção internacional (Ver Curtin, 1968; Fett, 2002; Kiple, 1984 e 1988 e Kiple \& King, 1981; McBride, 2005; Morais, 1967; Numbers \& Savitt, 1989; Savitt, 1978 e 2005; Sheridan, 1985). As obras analisam a história da saúde e das doenças dos escravos em perspectiva abrangente. Abordam temas tais como a relação entre medicina e escravidão e a história biológica da raça negra.

A ausência de estudos mais alentados sobre a saúde do escravo na historiografia brasileira talvez seja decorrência da desatenção que a questão da assistência médica à força de trabalho escrava teve ao longo do período da escravidão, como apontamos no início deste ensaio. Com exceção do estudo de Mary Karasch (2000, 1. ed. 1987) que dedicou um largo espaço à questão, e mais recentemente o 
de Jaime Rodrigues (2005), os tratados sobre a escravidão no Brasil passam ao largo dessa questão. Mas da sólida documentação sobre a escravidão que podemos encontrar nos arquivos brasileiros, associada à atual multiplicidade de trabalhos acadêmicos sobre o tema da saúde e da doença - consubstanciados em uma série de publicações sobre a história da medicina e as artes de curar no Brasil -, do cruzamento das fontes e dos temas, podemos traçar a história da vida higiênica dos escravos no Brasil do século XIX. Este é o objetivo do projeto ora iniciado na Casa de Oswaldo Cruz/Fiocruz: "O sistema de saúde do escravo no Brasil do século XIX: instituições e práticas terapêuticas".

\section{REFERÊNCIAS BIBLIOGRÁFICAS}

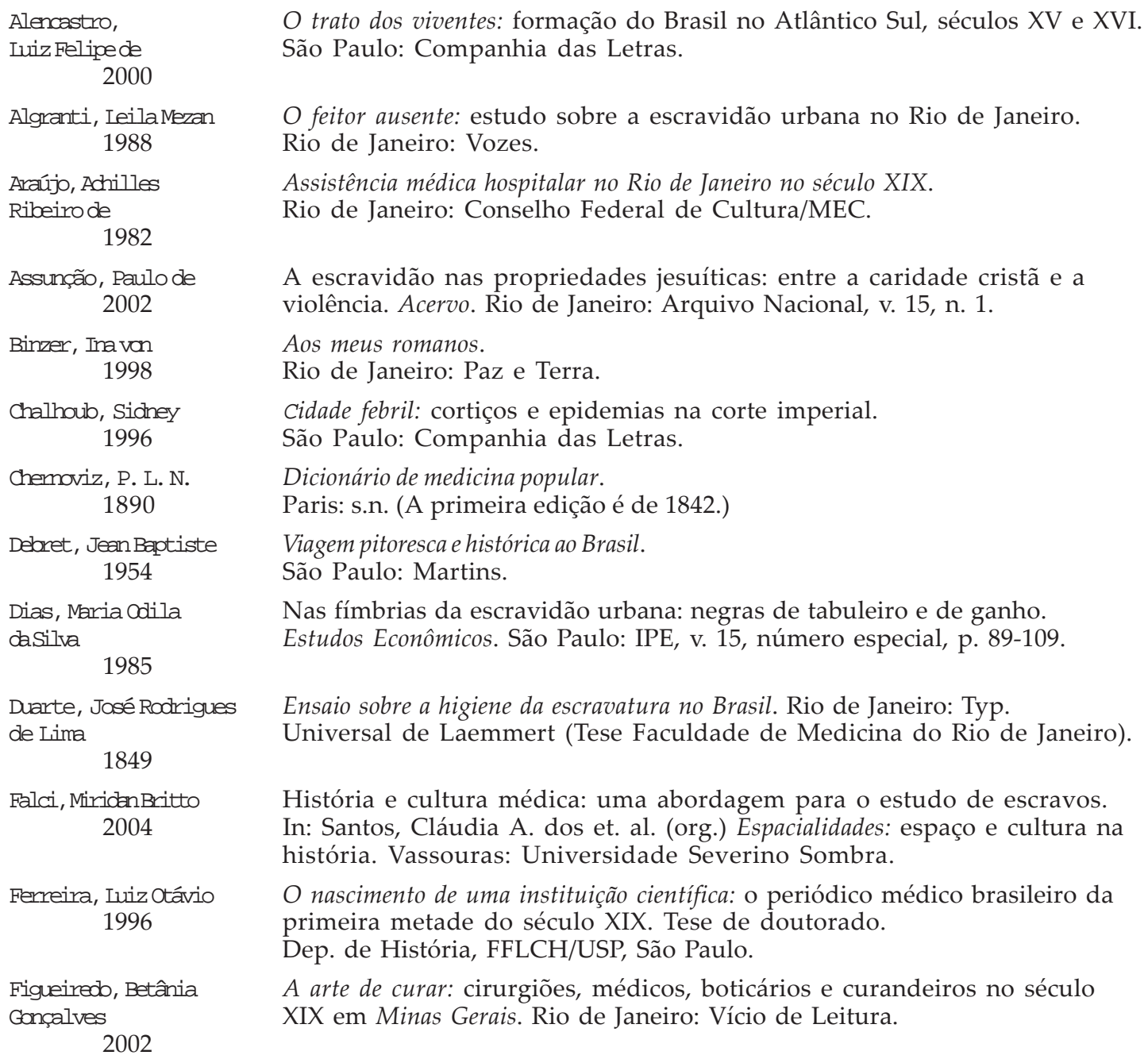

Alencastro, Iuiz Felipe de 2000

Algranti, Leila Mezan 1988

Araújo, Achilles Ribeiro de 1982

Assunção, Paulo de 2002

Binzer, Ina von 1998

Chalhoub, Sidney 1996

Chemoviz, P. L. N. 1890

Debret, Jean Baptiste 1954

Dias, Maria Odila da.silva 1985

Duarte, José Rodrigues de Lima 1849

Falci, Miridan Britto 2004

Ferreira, Luiz Otávio 1996

Figueiredb, Betânia Gonçalves

O trato dos viventes: formação do Brasil no Atlântico Sul, séculos XV e XVI. São Paulo: Companhia das Letras.

O feitor ausente: estudo sobre a escravidão urbana no Rio de Janeiro. Rio de Janeiro: Vozes.

Assistência médica hospitalar no Rio de Janeiro no século XIX. Rio de Janeiro: Conselho Federal de Cultura/MEC.

A escravidão nas propriedades jesuíticas: entre a caridade cristã e a violência. Acervo. Rio de Janeiro: Arquivo Nacional, v. 15, n. 1.

Aos meus romanos.

Rio de Janeiro: Paz e Terra.

cidade febril: cortiços e epidemias na corte imperial.

São Paulo: Companhia das Letras.

Dicionário de medicina popular.

Paris: s.n. (A primeira edição é de 1842.)

Viagem pitoresca e histórica ao Brasil.

São Paulo: Martins.

Nas fímbrias da escravidão urbana: negras de tabuleiro e de ganho.

Estudos Econômicos. São Paulo: IPE, v. 15, número especial, p. 89-109.

Ensaio sobre a higiene da escravatura no Brasil. Rio de Janeiro: Typ.

Universal de Laemmert (Tese Faculdade de Medicina do Rio de Janeiro).

História e cultura médica: uma abordagem para o estudo de escravos. In: Santos, Cláudia A. dos et. al. (org.) Espacialidades: espaço e cultura na história. Vassouras: Universidade Severino Sombra.

O nascimento de uma instituição científica: o periódico médico brasileiro da primeira metade do século XIX. Tese de doutorado. Dep. de História, FFLCH/USP, São Paulo.

$A$ arte de curar: cirurgiões, médicos, boticários e curandeiros no século XIX em Minas Gerais. Rio de Janeiro: Vício de Leitura. 
Fonseca, Antônio

Caetano da 1863

Freitas, Octavio de 1935

Freyre, Gillberto

1933

Imbert, J. B. A. 1834

Jardim, David Gomes 1847

Karasch, Mary 2000

Kiple, Kenneth $F$. 1988

Kiple, Kenneth $F$. 1984

Kiple, Kenneth F. \& King, Virginia Himmelsteib 1981

Langgard, T. J. H. 1873

Machado Roberto et al. 1976

Maio, Marcos Chor 2004

Marques, Xavier 1922

Mattoso, Kátia M. . de Queirós 1982

Montero, Paula 1983

Parahym, Orlando 1978

Pimenta, T. S. 2003

Pimenta, T. S. 1998

Pôrto, Ângela 1988

Rodrigues, Nina 2004

Rodrigues, Nina 1935
Manual do agricultor dos gêneros alimentícios ou método da cultura mixta destes gêneros nas terras causadas pelo sistema vegeto-animal; modo de criar e tratar o gado, e um pequeno tratado de medicina doméstica para fazendeiros. Rio de Janeiro: Ed. Eduardo \& Henrique Laemmert.

Doenças africanas no Brasil.

São Paulo: Cia Ed. Nacional.

Casa grande $\mathcal{E}$ senzala.

Rio de Janeiro: Maia \& Schmidt Ltda.

Manual do fazendeiro ou tratado doméstico sobre as enfermidades dos negros.

Rio de Janeiro: Typ. Nacional e Const. De Seignot-Plancher e Cia.

A higiene dos escravos.

Rio de Janeiro, Tese Faculdade de Medicina do Rio de Janeiro.

A vida dos escravos no Rio de Janeiro (1808-1850).

São Paulo: Companhia das Letras.

The African exchange: toward a biological history of black people.

Durham: Duke University Press.

The Caribbean slave: a biological history.

Cambridge: Cambridge University Press.

Another dimension to the black diaspora: diet, disease, and racism.

Cambridge: Cambridge University Press.

Dicionário de medicina doméstica e popular.

Rio de Janeiro: s.n.

Danação da norma: medicina social e constituição da psiquiatria no Brasil. Rio de Janeiro: Graal. Parte II, cap. 2.

Raça, doença e saúde pública no Brasil: um debate sobre o pensamento higienista do século XIX. In: Monteiro, Simone (org.) Etnicidade na América Latina: um debate sobre raça, saúde e direitos reprodutivos. Rio de Janeiro: Ed. Fiocruz. p. 15-45.

Ofeiticeiro.

Rio de Janeiro: Liv. Leste Ribeiro.

Ser escravo no Brasil.

São Paulo: Brasiliense.

Da doença à desordem: as práticas mágico-terapêuticas na umbanda.

São Paulo: Edusp.

Doenças dos escravos em Pemambuco.

Recife: Caxangá.

Terapeutas populares e instituições médicas na primeira metade do século XIX. In: Chalhoub, Sidney et al. (org.). Artes e ofícios de curar no Brasil. Campinas: Ed. Campinas. p. 307-30.

Barbeiros-sangradores e curandeiros no Brasil (1808-1828). História, Ciências, Saúde-Manguinhos, Rio de Janeiro, v. 5, n. 2.

A assistência médica aos escravos no Rio de Janeiro: o tratamento homeopático. Rio de Janeiro; Fundação Casa de Rui Barbosa (Papéis Avulsos, 7).

Os africanos no Brasil.

Brasília: Ed. UnB.

O animismo fetichista dos negros baianos.

Rio de Janeiro: Civilização Brasileira. 


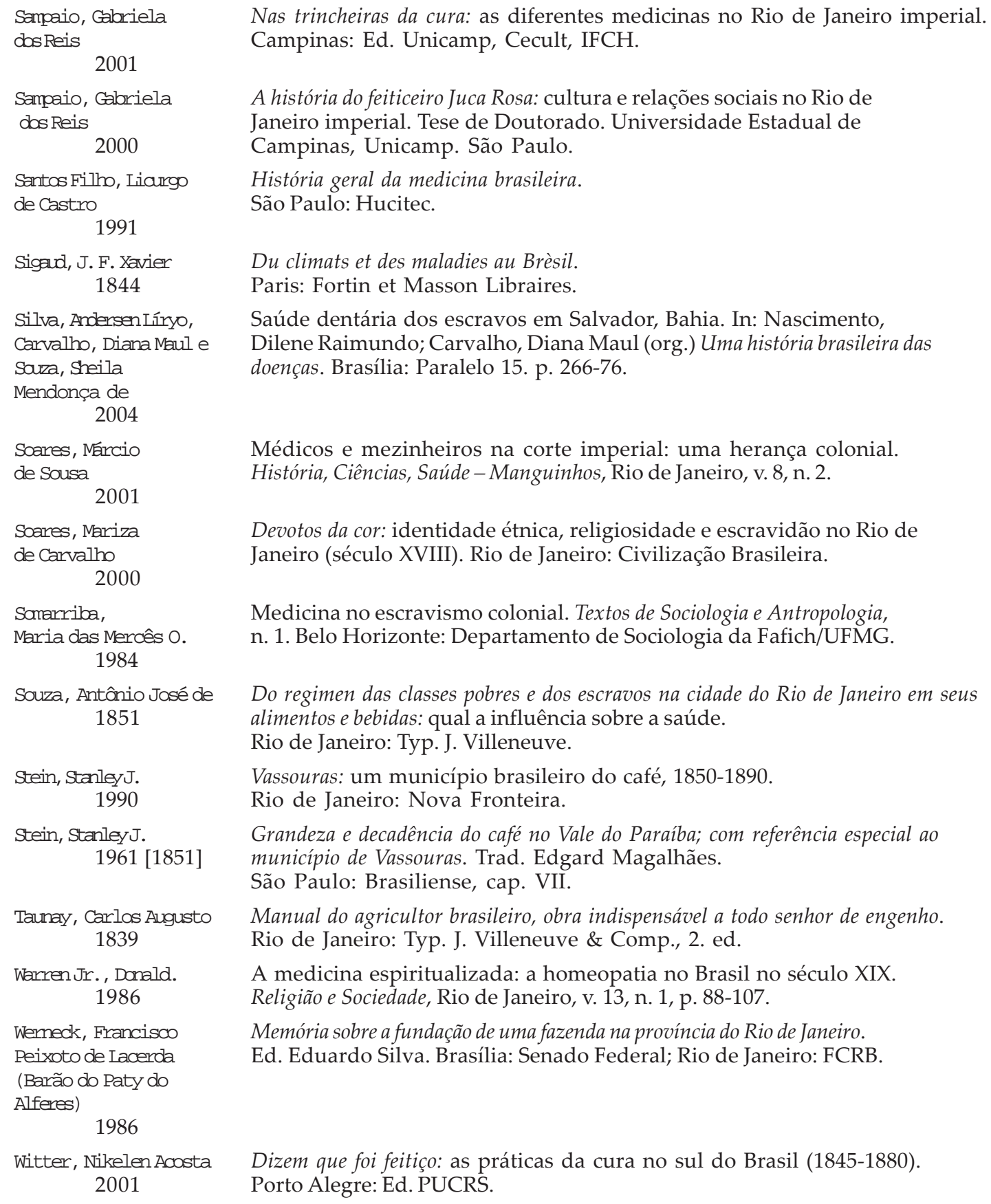

